\title{
RELACIONES ECONÓMICAS ENTRE CHINA Y MÉXICO ANTE LA PERSPECTIVA DE UN ACUERDO COMERCIAL
}

\author{
Liu Xuedong \\ Universidad Nacional Autónoma de México
}

\section{RESUMEN}

En la actualidad China y México están considerados como economías emergentes con un enorme grado de apertura comercial, cuyo lazo económico no solamente consiste en conservar los intercambios comerciales de manera directa, sino también de manera indirecta por medio de sus respectivas participaciones activas en las cadenas globales importantes. Ante el acuerdo comercial alcanzado entre México y los Estados Unidos en agosto pasado, con el contexto de la modernización del Tratado del Libre Comercio en la América del Norte (TLCAN), el panorama de crecimiento económico y de la entrada de inversión extranjera se vio esclarecido paulatinamente, y se espera un fortalecimiento aún mayor de los vínculos económicos entre México y su vecino del Norte. Por su parte, la necesidad de diversificar la economía mexicana, sobre todo para incursionar en los nuevos mercados a escala internacional, se ha intensificado cada vez más y hoy se requiere realizar un esfuerzo aún mayor.

En este estudio se pretende analizar las principales características registradas en las relaciones económicas sostenidas durante los últimos 20 años entre China y México, especialmente en el ámbito del comercio bilateral, ya que ha sido la parte medular de los vínculos económicos de las dos economías. Como se podrá observar, los intercambios comerciales entre las dos naciones se han concentrado en los productos intermedios y del capital, además, un reducido número de sectores explica la mayor parte del desequilibrio creciente de la cuenta corriente de mercancías a favor del país asiático. 
En la primera parte de este trabajo se presentan las características principales arrojadas por las relaciones económicas desde el inicio de este nuevo milenio, concentradas en tres sectores principales: los capítulos 84, 85 y 87 del SA; ${ }^{1}$ enseguida, se analizan los intercambios comerciales para los mismos productos sostenidos entre México y los Estados Unidos, y finalmente se plantean las perspectivas de los vínculos económicos, especialmente en el aspecto de los intercambios comerciales entre China y México.

\section{PANORAMA GENERAL DE LOS VÍNCULOS ECONÓMICOS ENTRE CHINA Y MÉXICO}

Los vínculos económicos entre China y México han estado creciendo y consolidándose de manera importante durante las últimas dos décadas, sobre todo en el aspecto de los intercambios comerciales. En este sentido, los desequilibrios encontrados registran una creciente tendencia a favor del país asiático; algunas de sus principales características son: los productos intermedios y del capital han formado los principales objetos, un número reducido de sectores ha propiciado un ritmo cada vez más dinámico en el comercio bilateral, los flujos de inversiones bilaterales se han desarrollado de manera insignificante en comparación con otras economías de América Latina, etcétera.

\section{Intercambios comerciales crecientes contrastan con la escasa inversión}

De acuerdo con las cifras de la Secretaría de Economía, en el año 2000 el volumen total de comercio bilateral (las importaciones más las exportaciones de las dos economías) fue de apenas 3083.2 millones de dólares, esto es, $0.9 \%$ del total que registraba el comercio exterior de México con el resto del mundo. Sin embargo, para 2017 estas cifras fueron de 80557.8 millones de dólares, 9.87\%, y en un lapso de 17 años la importancia de los intercambios comerciales entre ambas economías se ha multiplicado por más de 10 veces para México. ${ }^{2}$

${ }^{1}$ El Sistema Armonizado de Designación y Codificación de Mercancías, llamado también Sistema Armonizado o SA, es una nomenclatura internacional de mercancías creada por la Organización Mundial de Aduanas (OMA). Más de 200 países utilizan este sistema, con el que se busca tener una clasificación uniforme. El SA es regulado por el Convenio Internacional del Sistema Armonizado de Designación y Codificación de Mercancías. La OMA se encarga, por medio del Comité del Sistema Armonizado, de su mantenimiento y actualización mediante enmiendas y transposiciones, de modo que refleje los desarrollos tecnológicos y los cambios en el comercio. Convenio del Sistema Armonizado (SA). Recuperado de http://tfig.unece.org/SP/contents/HS-convention.htm

2 Secretaría de Economía, Sistema de Consulta de Información Estadística por País. 
En cuanto a las importaciones procedentes de China, el volumen aumentó de 4027.3 a 74145.3 millones de dólares en los dos años señalados; es decir, una tasa del crecimiento acumulado de 27.5 veces. Por su parte, los envíos de México al país asiático subieron de 203.6 millones de dólares a 6412.5 millones de dólares, o sea 31.5 veces más en el mismo lapso (gráfica 1).

GRÁFICA 1. Comercio bilateral entre China y México, 2000-2017

(millones de dólares)

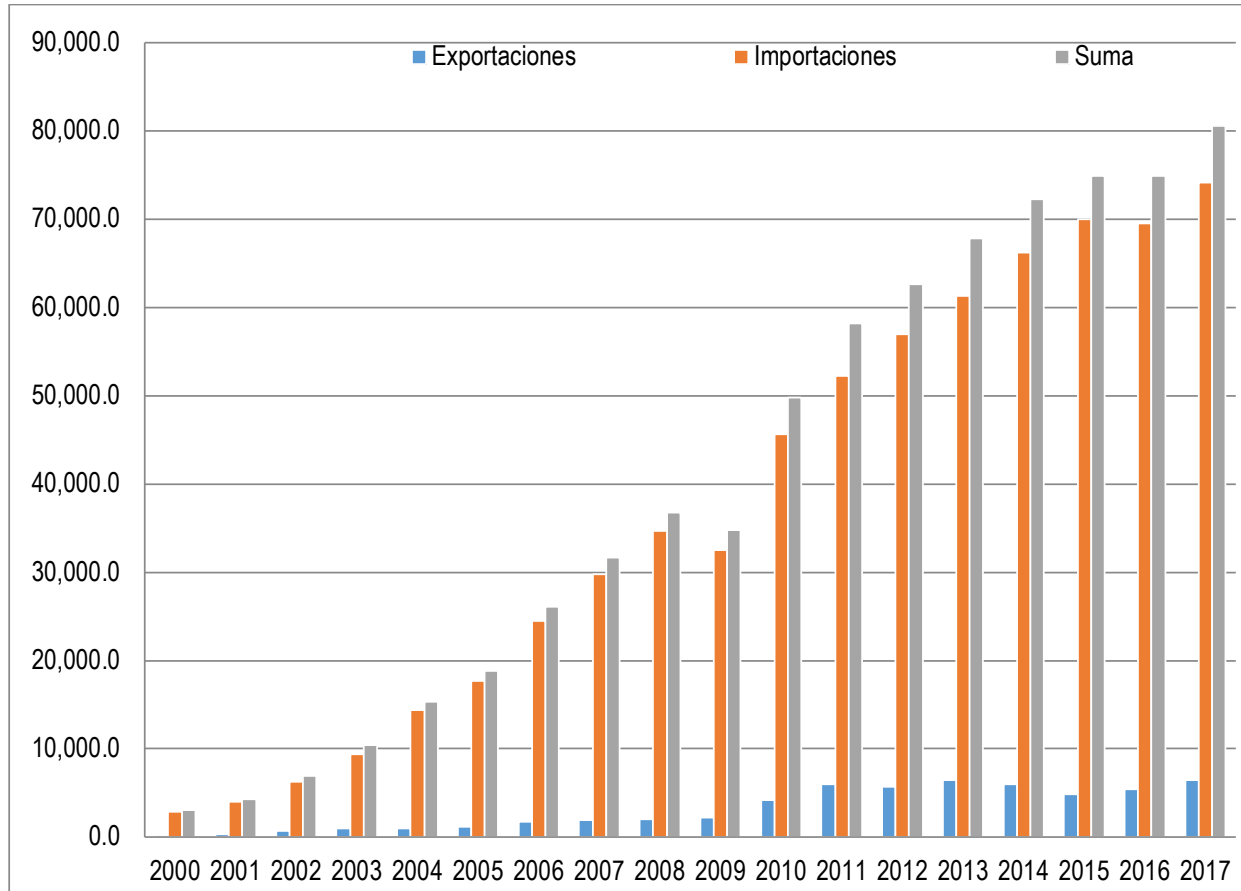

FUENTE: Secretaría de Economía.

Cabe mencionar que la creciente importancia del comercio entre las dos economías no solamente se refleja por la comparación histórica propia registrada, sino también se puede visualizar mediante el análisis transversal para las economías de América Latina. Los datos estadísticos de Naciones Unidas revelan que en 2014 los intercambios comerciales entre China, América Latina y el Caribe alcanzaron un volumen superior a 277 mil millones de dólares, de los cuales México representaba 26.1\%, cifra apenas inferior a la registrada por Brasil, de $28.1 \%$. Por otro lado, si se revisan los datos de la balanza comercial se puede encontrar que, a nivel general América Latina mantiene un déficit comercial con China de 
82.1 mil millones de dólares, de los cuales México representa casi las tres cuartas partes, mientras Brasil muestra un superávit de 3.3 mil millones de dólares (cuadro 1). ${ }^{1}$

CUADRO 1. Estructura de los intercambios comerciales entre China y América Latina, por país, $2014(\%)$

\begin{tabular}{|l|c|c|}
\hline \multicolumn{1}{|c|}{ Paises } & Volumen & Balanza comercial \\
\hline Total & 100.0 & 100.0 \\
\hline México & 26.1 & 73.4 \\
\hline Brasil & 28.1 & -4.0 \\
\hline Chile & 12.2 & -4.5 \\
\hline Argentina & 5.5 & 7.6 \\
\hline Colombia & 6.3 & 7.4 \\
\hline Ecuador & 1.8 & 5.0 \\
\hline Paraguay & 1.1 & 3.7 \\
\hline Perú & 5.8 & 2.3 \\
\hline Resto & 13.1 & 9.1 \\
\hline
\end{tabular}

FUENTE: Elaboración propia a partir de las cifras de Comtrade (2015) citadas por A. Roldán et al. (2016), Presencia de China en América Latina, comercio, inversión y cooperación económica, p. 33, tabla 2.2, Colombia.

Desde el ámbito de las inversiones extranjeras realizadas en América Latina por China, Brasil sigue siendo el receptor principal. De 2001 a 2016 China ha canalizado un total de 113662 millones de dólares por concepto de inversiones directas en el extranjero (Outward Foreign Direct Investment, OFDI) en países latinoamericanos, entre los cuales el destino principal ha sido Brasil, con una participación de 48.3\%; seguido de Perú, Argentina, Cuba, Jamaica y Chile, con 10.9, 9.3, 5.1, 4.3 y $2.9 \%$, respectivamente; México está en la sexta posición, con 2.8 por ciento (gráfica 2 ).

${ }^{1}$ Naciones Unidas, Comtrade. 
GRÁFICA 2. Estructura de la OFDI china en América Latina, por país, 2001-2016 (\%)

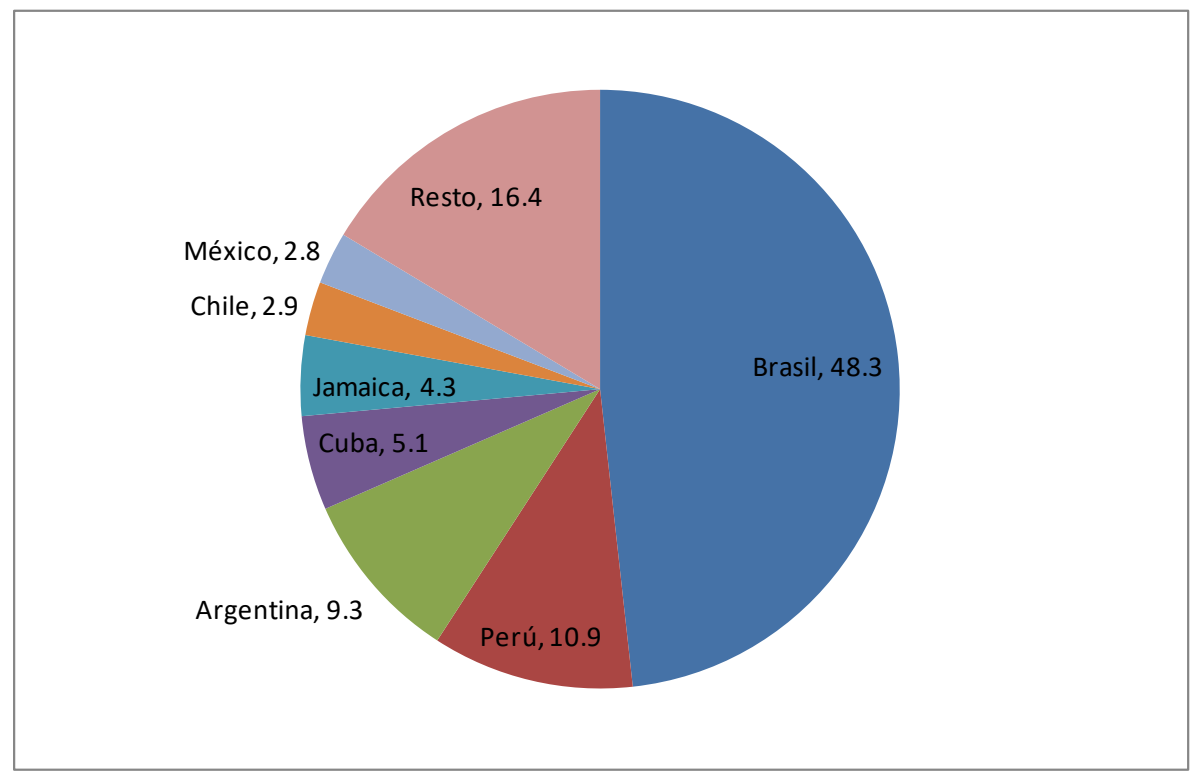

Fuente: P. E. Dussel y V. S. Ortiz (2017), Monitor de la OFDI de China en América Latina y el Caribe, p. 7, Red Académica de América Latina y el Caribe sobre China (Red ALC-China), México, junio 8. Recuperado de http://www.redalcchina.org/monitor/images/pdfs/menuprincipal/DusselPeters_OrtizVelasquez_2017_Monitor OFDIchinaALC_Espanol.pdf.

Lo anterior demuestra que entre Brasil y México existe una gran diferencia en cuanto a sus vínculos económicos con China. Por un lado, en América del Sur, en relación con los intercambios comerciales y las inversiones recibidas, los vínculos concuerdan en la importancia de la economía brasileña en la región. Por otro lado, México se ha concentrado principalmente en los intercambios comerciales, mientras que la recepción de las inversiones chinas ha disminuido relativamente en comparación con el peso que representa la economía mexicana en América Latina y el Caribe. Además, en el comercio entre las dos economías en cuestión México se ha mostrado cada vez más deficitario (gráfica 3). 
GRÁFICA 3. Saldo deficitario para México en su comercio con China, 1993-2016 (millones de dólares)

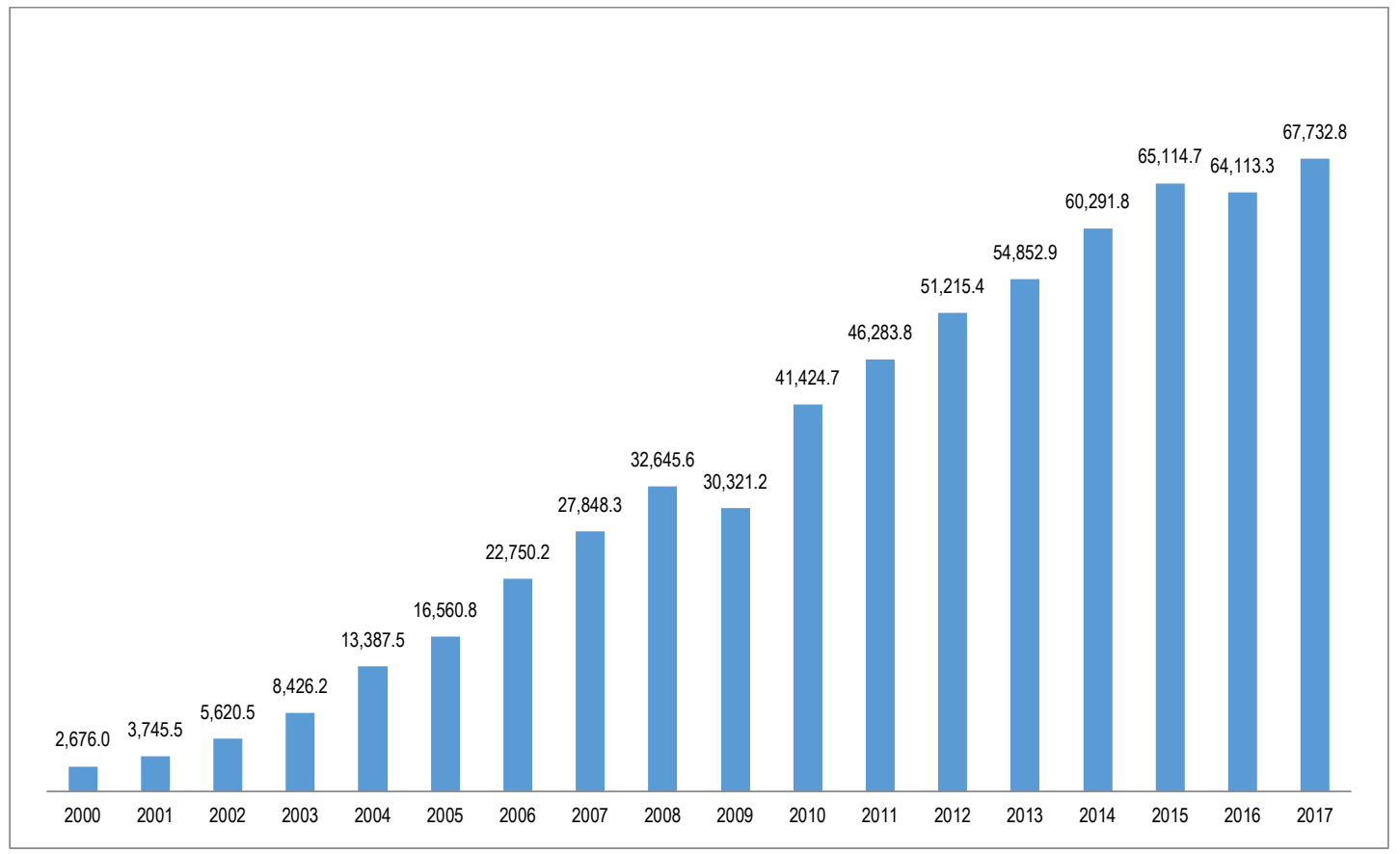

FUENTE: Elaboración propia a partir de la información proporcionada por la Secretaría de Economía-Sistema de Consulta de Información Estadística por País.

Sectores principales del comercio entre China y México

Las características registradas por los vínculos económicos entre China y México, tal como se analizaron, no resultaron de la casualidad, sino que han sido producto de una secuela de varios elementos relacionados tanto con China como con México. Por parte de China, de acuerdo con el avance en el proceso de modernización llevado a cabo por las dos economías, los productos clasificados como bienes intermedios y de capital han tenido una creciente participación en el total del comercio exterior bilateral, ya que en términos integrales los productos procedentes de China han sido cada vez más competitivos en el ámbito internacional debido a las ventajas registradas en el costo de contenidos tecnológicos y de calidad.

En el caso de México, el sector manufacturero se encuentra en una etapa de crecimiento constante y de consolidación, sobre todo para las ramas destinadas a las exportaciones. Con el objetivo de promover una mayor presencia de estos productos en los mercados 
internacionales, las deficiencias que han tenido las cadenas productivas en la mayoría de las ocasiones tienen que buscar opciones para proveer los insumos, bienes de intermedio y de capital, etc., fuera del país, a fin de formar cadenas competitivas. Por ello, en comparación con otras economías de América Latina, México ha afianzado sus vínculos económicos con China mediante los intercambios comerciales, especialmente en los bienes intermedios y de capital. De acuerdo con estimaciones diversas, la participación de este tipo de productos en el total de los saldos deficitarios registrados anualmente de México con China, ya se ubica por arriba de 90 por ciento.

$\mathrm{Si}$ se toman los valores de intercambios comerciales entre México y China en los capítulos 84,85 y 87 , respectivamente, se pueden explicar alrededor de $70 \%$ de los saldos deficitarios registrados en México con el país asiático. En el periodo de análisis de 20032017, la información que otorga el Sistema de Información Arancelaria Vía Internet (SIAVI 4), de la Secretaría de Economía, revela que el nivel de importancia de estos tres sectores económicos no ha tenido cambios significativos en México en cuanto a las importaciones y las exportaciones con China. En 2003 los envíos mexicanos al mercado chino representaban una participación de $45.94 \%$ del total, mientras que las importaciones fueron de $69.80 \%$; para 2017 las cifras respectivas se situaban en 43.60 y $66.82 \%$ respectivamente.

Si bien en ambos casos la importancia ha significado una disminución de 2.34 y 2.98 puntos porcentuales en el lapso de 14 años, después de revisar las cifras registradas en el mismo periodo, pero en relación con los intercambios comerciales realizados entre México y las economías distintas del país asiático, los vínculos económicos en estos sectores particulares se han acentuado. En 2003, para los productos clasificados en los capítulos 84, 85 y 87, las importaciones procedentes de China fueron de $11.22,8.47$ y $0.82 \%$, respectivamente, del total de las compras realizadas por México. Sin embargo, en 2017 las mismas cifras subieron hasta 23.24, 35.52 y 7.40\% para los tres sectores (gráfica 4). Lo anterior indica que México ha aumentado la compra de productos chinos a costa de los de las demás economías de mundo, al bajar su participación de $88.78,91.53$ y $99.18 \%$ en 2003, a $76.74,64.48$ y $92.60 \%$ en 2017 , con una disminución neta de $12.04,27.05$ y 6.58 puntos porcentuales. 
GRÁFICA 4. Importancia de los productos chinos en las importaciones mexicanas, en los sectores 84,85 y 87 (2003-2017) (\%)

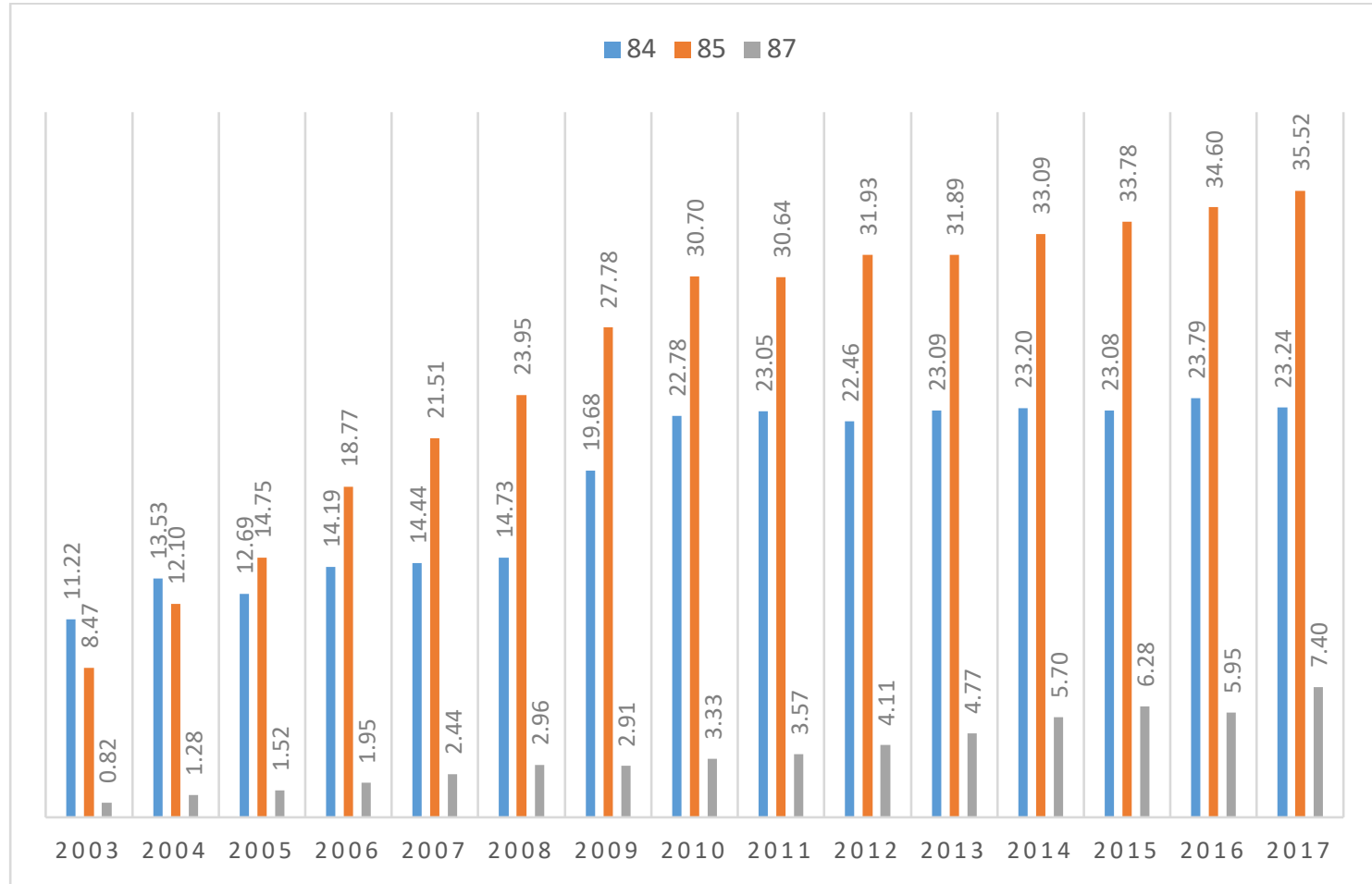

FUENTE: Secretaría de Economía, Sistema de Información Arancelaria Vía Internet (SIAVI 4).

Cabe mencionar que, en el periodo de análisis, se puede observar que los productos del capítulo 85, es decir las maquinas, aparatos y material eléctrico y sus partes; aparatos de grabación o reproducción de sonido; aparatos de grabación o reproducción de imágenes y sonido en televisión, y las partes y accesorios de estos aparatos, tuvieron un comportamiento dinámico y sobresaliente; en conjunto, estos artículos procedentes de China han ganado una participación de 27.05 puntos porcentuales. Actualmente, del total de las importaciones que realiza México de este grupo de mercancías, más de un tercio es de origen chino. Por su parte, los sectores 84 y 87 también han incrementado sus participaciones, al pasar de 11.22 y $0.82 \%$ en 2003 , a 23.24 y $7.40 \%$, en 2017 , respectivamente.

Lo anterior contrasta con la poca importancia que otorgan esas tres grandes categorías en los intercambios comerciales sostenidos entre China y México, de 2003 a 2017 . Una explicación de esta "aparente inconsistencia" es que las dos economías muy probablemente se han encontrado en un proceso de mayor diversificación en sus comercios bilaterales. En 
otras palabras, a pesar de que siguen siendo los principales ramos los productos clasificados en los capítulos 84,85 y 87 dentro de los intercambios, otros productos han contribuido cada vez con mayor dinámica e importancia tanto a las importaciones como a las exportaciones mexicanas efectuadas con China.

Finalmente, en cuanto a la balanza comercial para los mismos productos analizados hasta ahora, merece mención especial lo siguiente: en 2017, los intercambios comerciales llevados a cabo bilateralmente en los capítulos 84,85 y 87 generaban un saldo deficitario de 1 1553.4, 29351.6 y 1840.0 millones de dólares, respectivamente, para México. Esto es, un déficit de 4674.5 millones de dólares en total, lo que representa 69.01 por ciento.

\section{LA OTRA CARA DE LA MONEDA: LOS INTERCAMBIOS COMERCIALES ENTRE MÉXICO Y LOS ESTADOS UNIDOS EN LOS SECTORES 84, 85 Y 87}

En los mencionados sectores 84,85 y 87 , los intercambios comerciales realizados entre México y los Estados Unidos han registrado un panorama totalmente distinto a lo observado entre México y China: en lugar de sostener un saldo deficitario, México ha sido superavitario durante los últimos 15 años, con un saldo promedio anual de 88208.7 millones de dólares, al pasar de un total de 39983.9 en 2003, a 141289.4 en 2017, ambas cifras en millones de dólares (cuadro 2), con una tasa de crecimiento promedio de 9.43 por ciento anual. 
CuAdro 2. Balanza comercial entre México y China y entre México y los Estados Unidos, en los sectores 84,85 y 87 (2003-2017)

(millones de dólares)

\begin{tabular}{|c|c|c|c|c|c|c|c|c|}
\hline \multirow[b]{2}{*}{ Año } & \multicolumn{2}{|c|}{ Sector 84} & \multicolumn{2}{|c|}{ Sector 85} & \multicolumn{2}{|c|}{ Sector 87} & \multicolumn{2}{|c|}{ Suma } \\
\hline & China & $E U A$ & China & $E E U U$ & China & $E U A$ & China & $E U A$ \\
\hline 2003 & -2887.5 & 7769.5 & -3136.6 & 17904.2 & -89.7 & 14310.3 & -6113.8 & 39983.9 \\
\hline 2004 & -4245.5 & 10140.8 & -5306.1 & 23754.8 & -209.7 & 15063.5 & -9761.3 & 48959.1 \\
\hline 2005 & -4271.0 & 8633.8 & -7071.7 & 29646.0 & -284.2 & 15957.4 & -11626.9 & 54237.1 \\
\hline 2006 & -5251.9 & 9336.8 & -10523.8 & 36337.3 & -288.7 & 20332.7 & -16064.3 & 66006.7 \\
\hline 2007 & -5741.7 & 9787.0 & -12728.1 & 43042.1 & -441.7 & 18709.2 & -18911.4 & 71538.2 \\
\hline 2008 & -6560.7 & 8816.3 & -15206.3 & 45004.7 & -604.7 & 18603.2 & -22371.7 & 72424.2 \\
\hline 2009 & -7075.7 & 10170.1 & -15097.4 & 35538.2 & -328.8 & 17499.3 & -22502.0 & 63207.6 \\
\hline 2010 & -10459.9 & 17503.4 & -21456.1 & 41072.3 & -183.2 & 27466.6 & -32099.2 & 86042.3 \\
\hline 2011 & -12244.4 & 20508.9 & -22889.2 & 39469.5 & -128.0 & 30864.5 & -35261.6 & 90842.9 \\
\hline 2012 & -13363.8 & 21784.5 & -23972.2 & 41685.1 & -396.5 & 35120.1 & -37732.5 & 98589.6 \\
\hline 2013 & -14170.3 & 22308.5 & -26017.9 & 44400.6 & 23.3 & 43080.2 & -40164.9 & 109789.2 \\
\hline 2014 & -14966.7 & 25834.7 & -27728.7 & 47235.2 & 148.3 & 50325.2 & -42547.0 & 123395.1 \\
\hline 2015 & -15252.0 & 24262.8 & -28380.8 & 48131.0 & -907.6 & 55765.2 & -44540.4 & 128159.0 \\
\hline 2016 & -15497.4 & 28352.1 & -28384.2 & 45348.0 & -1041.8 & 54965.4 & -44923.5 & 128665.5 \\
\hline 2017 & -15553.4 & 30511.7 & -29351.6 & 48460.7 & -1840.4 & 62317.0 & -46745.4 & 141289.4 \\
\hline $\begin{array}{c}\text { Coeficiente } \\
\text { de } \\
\text { correlación }\end{array}$ & -0.9 & & & & & & -0 & 723 \\
\hline
\end{tabular}

FUENTE: Secretaría de Economía, Sistema de Información Arancelaria Vía Internet (SIAVI 4).

Ante este panorama, se pretende establecer una hipótesis en el sentido de que los saldos deficitarios y los superavitarios registrados por México en sus intercambios comerciales bilaterales con China y con los Estados Unidos están directamente interrelacionados, sobre todo en los sectores analizados. En primera instancia esto se ve complicado, sobre todo si se 
consideran los patrones aparentemente distintos entre los dos flujos comerciales; sin embargo, con base en los siguientes hechos es posible deducir tal afirmación de manera significativa, sobre todo porque la ha confirmado el alto coeficiente de correlación registrado, en particular para los productos incluidos en los capítulos 84 y 85 , de -0.9712 y- 0.8728 , respectivamente.

En primer lugar, tanto México como China se muestran como partes activas y dinámicas en sus respectivas participaciones, en cuanto a la formación de valiosas cadenas globales, debido a las políticas de apertura comercial instrumentadas desde hace más de tres décadas, a pesar de ser de manera diferente. Por ello, se puede inferir que los productos de procedencia china importados por México están considerados como insumos intermedios para los eslabones productivos instalados en México. Después de llevar a cabo las integraciones respectivas de los bienes importados, los productos finales se destinan a satisfacer la demanda mundial, incluyendo a México y China.

En segundo lugar, ante el incremento significativo del nivel salarial efectuado en China, la mano de obra es cada vez más costosa en comparación con la vigente en México. Por ello se puede observar que durante los últimos años, sobre todo después de 2008, inversiones extranjeras directas relacionadas con los artículos de los tres capítulos han entrado a México con importantes volúmenes de éstos. Asimismo, la importación de los respectivos productos de China y los envíos de productos mexicanos al mercado de América también empezaban a crecer significativamente; ello explica por qué México recuperó inmediatamente en 2010 el nivel anterior de las exportaciones hacia el mercado de los Estados Unidos, después de haber sido afectado por la crisis financiera de 2008.

En cuanto a la importancia de los envíos de productos mexicanos a los mercados estadounidenses, estos tres sectores representaban una participación de $64.18 \%$ del total de 2017. Por su parte, los mismos productos importados por México procedentes de su vecino del norte, significaban una participación de $65.02 \%$ del total de los tres sectores en el mismo año (cuadro 3). 
CUADRO 3. Importancia de los sectores 84, 85 y 87 en el comercio entre México y los Estados Unidos (2003-2017) (\%)

\begin{tabular}{|c|c|c|c|c|c|c|c|c|}
\hline & \multicolumn{6}{|c|}{ Exportaciones mexicanas a EUA } & \multicolumn{3}{|c|}{ Importaciones mexicanas de EUA } \\
\cline { 2 - 9 } Año & 84 & 85 & 87 & Suma & 84 & 85 & 87 & Suma \\
\hline $\mathbf{2 0 0 3}$ & 15.45 & 27.12 & 16.88 & 59.45 & 13.78 & 20.15 & 9.54 & 43.47 \\
\hline 2004 & 15.74 & 26.62 & 15.75 & 58.11 & 14.96 & 19.02 & 10.30 & 44.28 \\
\hline 2005 & 13.86 & 26.14 & 15.36 & 55.36 & 15.96 & 17.40 & 11.62 & 44.98 \\
\hline 2006 & 13.19 & 26.45 & 16.09 & 55.73 & 17.66 & 18.68 & 13.04 & 49.39 \\
\hline 2007 & 12.97 & 28.24 & 15.06 & 56.26 & 18.17 & 18.95 & 14.13 & 51.25 \\
\hline 2008 & 12.46 & 27.86 & 14.06 & 54.38 & 19.24 & 19.03 & 13.51 & 51.78 \\
\hline 2009 & 13.68 & 27.34 & 14.72 & 55.74 & 14.38 & 14.30 & 9.25 & 37.93 \\
\hline 2010 & 15.28 & 25.09 & 17.19 & 57.55 & 18.00 & 17.85 & 12.87 & 48.72 \\
\hline 2011 & 15.42 & 21.90 & 17.13 & 54.45 & 20.71 & 19.57 & 15.31 & 55.59 \\
\hline 2012 & 16.34 & 21.93 & 18.53 & 56.80 & 23.95 & 20.35 & 17.29 & 61.59 \\
\hline 2013 & 15.82 & 22.17 & 20.64 & 58.63 & 23.78 & 20.87 & 17.78 & 62.43 \\
\hline 2014 & 16.56 & 21.88 & 22.03 & 60.48 & 25.53 & 21.28 & 18.81 & 65.63 \\
\hline 2015 & 16.53 & 23.21 & 24.46 & 64.21 & 25.45 & 22.37 & 18.79 & 66.61 \\
\hline 2016 & 17.86 & 22.13 & 24.32 & 64.31 & 24.40 & 20.54 & 17.68 & 62.62 \\
\hline 2017 & 17.65 & 21.31 & 25.23 & 64.18 & 25.79 & 20.11 & 19.12 & 65.02 \\
\hline
\end{tabular}

FUENTE: Secretaría de Economía, Sistema de Información Arancelaria Vía Internet (SIAVI 4).

\section{PERSPECTIVAS DE LAS RELACIONES ECONÓMICAS ENTRE CHINA Y MÉXICO}

Ante el acuerdo de relaciones comerciales alcanzado entre México y los Estados Unidos en agosto pasado, en el contexto de la modernización del Tratado de Libre Comercio de América 
del Norte (TLCAN), el panorama del crecimiento económico y de la entrada de inversión extranjera se ve esclarecido paulatinamente, y se espera un fortalecimiento aún mayor de estos vínculos económicos bilaterales en el futuro. Concretamente, en los tres sectores comerciales que se han venido analizando en este trabajo se observa que los intercambios comerciales entre México y China se encuentran en una etapa de complementariedad mutua dentro de las cadenas de producción globales importantes.

Por su parte, la necesidad de diversificar la economía mexicana, sobre todo en el aspecto de incursionar los nuevos mercados internacionales, se ha intensificado cada vez más, y se requiere todavía un mayor esfuerzo.

De ello, en primer lugar México necesita cada vez más que antes llevar a cabo la diversificación de sus comercios exteriores. En segundo lugar, es importante seguir el camino tradicional de obtener financiamiento de los mercados internacionales; no obstante, tampoco debe olvidarse la exploración de nuevos mecanismos y fuentes de financiamiento. Sin duda, lograr un mayor acercamiento con China y aprovechar las oportunidades de inversiones e intercambios comerciales brindados por la segunda economía mundial sería un reto importante por superar, no sólo para México, sino también para China.

Es un hecho que las economías que actualmente se encuentran vinculadas con México mediante diversos acuerdos de libre comercio han sido y seguirán siendo opciones de primer nivel al aplicar la estrategia de diversificación. También es un hecho que la mayoría de estos socios comerciales de México son economías desarrolladas y como tales sus mercados y sus cadenas de producción están ya consolidados. En este sentido, comenzar a establecer relaciones comerciales y de inversión con esos socios comerciales no será tarea fácil para México, pues en su caso se tendrían que sustituir las ya existentes, para enfrentar una competencia mayor.

No obstante, como segunda potencia económica en la actualidad, China es una economía emergente y sus oportunidades del negocio y de inversión no sólo han sido abundantes sino también, en su mayoría, de reciente creación. Desde este escenario, la competencia para México es igual que otras economías que tienen el propósito de incursionar en este mercado potencialmente atractivo, cuyo tamaño es extraordinariamente grande por el nivel de población y por el poder adquisitivo que representa esta economía asiática. 
Respecto a lo anterior, la nueva administración de México que tomará posesión a partir del 1 del diciembre de este año no debe subestimar la importancia de buscar mecanismos adicionales para ampliar y profundizar las cooperaciones económicas tanto bilaterales como multilaterales que actualmente se encuentran vigentes entre México y China. Considerando las características de la economía china, esta opción para diversificar la economía mexicana todavía puede ser verdaderamente viable y potencialmente benéfica.

\section{REFERENCIAS BIBLIOGRÁFICAS}

De la Cruz, G. J. L y V. Veintimilla (2014), Evaluación del TLCAN y la competencia con China, TLCAN, 20 AÑOS ¿Celebración, desencanto o replanteamiento?, Universidad Nacional Autónoma de México, pp. 151-496.

Dussel, P. E y V. Ortiz (2017), "Monitor de la OFDI de China en América Latina y el Caribe", Red Académica de América Latina y el Caribe sobre China (Red ALC-China), México, junio $\quad 8 . \quad$ Recuperado de $\quad<\mathrm{http}: / /$ www.redalcchina.org/monitor/images/pdfs/menuprincipal/DusselPeters_OrtizVelasquez_2017_M onitorofDIchinaALC_Espanol.pdf>.

Roldán, A., et al. (2016), Presencia de China en América Latina, comercio, inversión y cooperación económica, 1a. ed., Universidad EAFIT, Colombia. 